\title{
Squamous Cell Atypia Suggesting High-grade Lesions: Correlation of Morphological Data, HPV Test Results and Follow-up
}

\author{
Alameda $F^{1,2^{*}}$, Hernández $E^{1}$, Del Amo $E^{1,2}$, Bellosillo $B^{1,3}$, Serrano $L^{1}$ and Carreras $\mathbf{R}^{1,2}$ \\ ${ }^{1}$ Department of Pathology, and Obstetrics and Gynecology, Hospital del Mar, Barcelona, Spain \\ ${ }^{2}$ Autonomous University of Barcelona, Spain \\ ${ }^{3}$ Pompeu Fabra University, Barcelona Catalonia, Spain
}

*Corresponding author: Alameda F, Department of Pathology, c/Passeig Maritim 25-2908003 Barcelona, Spain, Tel: +34932483919; Fax: +34932483131; E-mail: falameda@hospitaldelmar.cat

Received date: Jan 19, 2016; Accepted date: Mar 08, 2016; Published date: Mar 18, 2016

Copyright: @ 2016 Alameda F, et al. This is an open-access article distributed under the terms of the Creative Commons Attribution License, which permits unrestricted use, distribution, and reproduction in any medium, provided the original author and source are credited.

\section{Abstract}

Background: Squamous cell atypia suggesting high-grade lesion (ASCH) is a cytological lesion, related to a high-grade lesion. Guidelines recommend performing a colposcopy in these cases, without HPV testing.

Objective: Here we sought to determine the value of the HPV test in ASCH cases and to correlate morphological data, the HPV test results, and the follow-up.

Methods: Ninety-six patients were diagnosed with $\mathrm{ASCH}$ using liquid-based cytology (Thin-Prep®). Hybrid Capture II was the HPV test used. The patients were followed up for 6 to 48 months (mean 24 months). The following cytological data were included: isolated cells; dyskeratosis; hyperchromasia; coarse chromatin; nuclear membrane irregularity; 3D alterations; and molding.

Results: The mean age of the patients was 37 years (range 15-78). Thirty-seven cases were 30 years old or younger. Follow-up was not available for 11 cases. Seventy two cases were HPV+. None of HPV- cases developed HSIL. The following cytological data showed statistical significance: coarse chromatin and HPV positivity ( $p=0.007)$; nuclear membrane irregularity and HSIL in the follow-up ( $p=0.015)$; and molding and HSIL in the follow-up in HPV+ cases $(p=0.046)$.

Conclusions: The HPV test is useful for ASCH cases. Some nuclear alterations in ASCH can predict HPV positivity and HSIL in the follow-up.

Keywords: Asch; HPV; Cytology; Morphology

\section{Introduction}

Squamous cell atypia suggesting high-grade lesion or ASCH is recognized by Bethesda [1]. It is diagnosed through a cytological smear which holds immature squamous cells or metaplastic cells in which cytological changes are suggestive but not conclusive of high-grade squamous lesion (HSIL). The criteria for ASCH were the same for HSIL but in ASCH cases not all the HSIL criteria are present. Thus, the differential diagnosis must be made in cases that mimic high-grade lesions, such as immature squamous metaplasia, atrophy with atypia, and cells with high nucleus/cytoplasm ratio. ASCH is a relevant condition as the biopsy of $38-74 \%$ of cases confirms the presence of a high-grade lesion [2-12].

Clinical guidelines indicate that these patients should be submitted to colposcopy and biopsy if necessary, but the HPV test is not indicated [13]. However, there is increasing evidence in the literature that the HPV test is useful for the management of ASCH patient cohorts [8,14-22]. In addition there are few studies that link the morphological/cytological features of ASCH with the HPV result and the follow-up of these patients $[23,24]$.
Here we studied the value of the HPV test in an ASCH patient cohort. We sought to determine whether there is a relationship between the morphological/cytological changes of ASCH, the HPV test result, and the follow-up of the patients.

\section{Materials and Methods}

Ninety-six patients diagnosed with ASCH from January to December 2012 were included. All the patients had a HPV test. Furthermore, these patients were followed up for 6 to 48 months and they underwent colposcopy, cytology and biopsy. During the followup, all HSIL cases diagnosed by a smear test were biopsied, and these diagnoses were confirmed with p16 immunostaining.

For the cytological assessment, we used the ThinPrep platform technical procedure with T-5000 (Hologic ${ }^{\circ}$, Malborough Mass.); automated staining of the slides with Leica" Autostainer (Leica, Weitzlar, Germany), and automated reading of the slides using the ThinPrep Imager System (Hologic', Malborough Mass).

To determine the HPV status, Hybrid Capture II (HCII) (Qiagen ${ }^{\circ}$ Limburg, the Netherlands) was used. HCIIHR (High-risk)-HPV TEST: Samples were previously treated with a conversion kit for this test, following the manufacturer's instructions. HCII is based on nucleic 
Citation: Hernández E, Del Amo E, Bellosillo B, Serrano L, Alameda F, et al. (2016) Squamous Cell Atypia Suggesting High-grade Lesions: Correlation of Morphological Data, HPV Test Results and Follow-up. J Cytol Histol 7: 396. doi:10.4172/2157-7099.1000396

Page 2 of 5

acid hybridization with signal amplification and detection by chemiluminescence in a microplate. The amount of light generated by the HCII assay is proportional to the target DNA in the specimen, and a linear range of quantification is achievable over approximately 4 logs, thereby allowing approximate measurement of viral load [25]. Signal strength in relative light units (RLUs) were compared to $1 \mathrm{pg} / \mathrm{ml} \mathrm{HPV+}$ controls (RLU/PC). Samples with ratios greater than one were considered positive, as described in detail previously [25].

The following morphological/cytological variables were evaluated: isolated cells; dyskeratosis; hyperchromasia; coarse chromatin; nuclear membrane irregularity; 3D alterations; and molding.

Social-demographical data about the patients were also collected. Among these data, we studied the nationality (Spaniard, Arabic, Eastern European or Latin-American, $\mathrm{n}=94$ ), civil status (married, divorced, single or widow, $\mathrm{n}=55$ ), number of sexual partners (we established various groups: group 1 (between 1 to 3 partners), group 2 (between 4 to 10 partners), and group 3 (more than 10 partners) $n=$ 56)), smoking habit (non-smoker, ex-smoker and current smoker (less than 10 , between $10-20$ or more than 20 cigarettes/day respectively), $n$ $=23$ ), and the type of contraception method used (mechanical, hormonal, or none, $\mathrm{n}=75$ ).

This work was approved for the Ethical Comitee for Clinical Research of the Hospital del Mar with a number 2015/6254.

\section{Results}

Ninety-six patients were diagnosed with ASCH during the study period. The mean age of the patients was 37 (range 15-78). Thirtyseven cases were 30 years old or younger $(38.5 \%)$ while 59 patients were over $30(61.5 \%)$. We had access to follow-up data from 85 of these patients, 34 of them had 30 years or less and 51 patients had more than 30 years. Sixty six women were HPV positive.

In the analysis of HPV results, we observed that $86.5 \%$ of the younger women were HPV+ while only $67.8 \%$ of patients over 30 were $(\mathrm{p}=0.052)$ were show in Table 1 .

\begin{tabular}{|l|l|l|l|}
\hline AGE (years) & HPV & & Total \\
\hline & POS $(\%)$ & NEG $(\%)$ & N (\%) \\
\hline$\leq 30$ & $32(86.5)$ & $5(13.5)$ & $37(100)$ \\
\hline$>30$ & $40(67.8)$ & $19(32.2)$ & $59(100)$ \\
\hline TOTAL & $72(75)$ & $24(25)$ & $96(100)$ \\
\hline$P=0.052$ & & \\
\hline
\end{tabular}

Table 1: Result of the determination of HPV by age.

Of the social-demographical factors studied, only civil status and the number of sexual partners were related to the development of HSIL during the follow-up Table 2 .

\begin{tabular}{|l|l|}
\hline Nationality $(\mathbf{n}=\mathbf{9 4})$ & $\mathbf{P}=\mathbf{0 . 7 6}$ \\
\hline Tobacco $(n=23)$ & $P=0.25$ \\
\hline CC type $(n=75)$ & $P=0.36$ \\
\hline Civil status $(n=55)$ & $P=0.03$ \\
\hline
\end{tabular}

Sexual partners $(n=56)$ $P=0.01$

Table 2: Socio-demographical factors related to HSIL in the follow-up.

Nationality: Spaniard/Non Spaniard; TOBACCO: Yes/no. CONTRACEPTIVE TYPE (CC): Type of contraception (Mechanicalhormonal/nocontraception); CIVIL STATUS: Married/non-married Sexual Partners: More or less than 10 partners. The results for patients with follow-up data are shown in Table 3.

\begin{tabular}{|l|l|l|l|l|l|l|}
\hline $\begin{array}{l}\text { AGE } \\
(\text { years })\end{array}$ & HPV (n) & MISS & NEG (\%) & LSIL (\%) & HSIL (\%) & TOTAL (\%) \\
\hline$\leq 30$ & POS (32) & 2 & $8(25)$ & $11(42.3)$ & $11(40.7)$ & $30(35.3)$ \\
\hline & NEG(5) & 1 & $2(6.3)$ & $2(7.7)$ & 0 & $4(4.7)$ \\
\hline$>30$ & POS (40) & 4 & $12(37.5)$ & $8(30.8)$ & $16(59.3)$ & $36(42,4)$ \\
\hline & NEG (19) & 4 & $10(31.3)$ & $5(19.2)$ & 0 & $15(17.6)$ \\
\hline TOTAL & POS (72) & 6 & $20(62.5)$ & $19(73)$ & $27(100)$ & $66(77.6)$ \\
\hline & NEG (24) & 5 & $12(37.5)$ & $7(27)$ & 0 & $19(22.4)$ \\
\hline TOTAL & 96 & 11 & 32 & 26 & 27 & 85 \\
\hline
\end{tabular}

Table 3: Follow-up data related to age and HPV test.

Sixty-six cases were HPV+ (77.6\%) and 19 were HPV- (22.4\%). Of all the patients, 58 did not develop high-grade lesions in the follow-up $(68.2 \%)$, and of these, 26 cases developed low-grade lesions (44.8\%) while 32 cases were negative in the follow-up (55.2\%).

\section{Results for HPV- cases $(n=19)$}

Four patients were 30 years old or younger and 15 patients were over 30 . Seven of the 19 cases (36.8\%) showed low-grade lesions in the follow-up (5 LSIL and 2 ASCUS), and 12 cases negative results (63.2\%). None of the patients developed HSIL.

\section{Results for HPV+ cases $(n=66)$}

Thirty patients were 30 years old or younger and 36 patients were over 30. During the follow-up, 27 patients (31.8\%) developed highgrade lesions (CIN2-3) of whom 16 were over 30 (31.4\%), and 11 under 30 (32.35\%). Thirty-nine cases did not develop HSIL, although 19 of them had a low-grade lesion.

As mentioned above, none of the HPV- cases developed HSIL in the follow-up ( $p=0.002$, Table 4 ). The sensitivity of HPV test for HSIL in our series was $100 \%$, the specificity $29.7 \%$, the negative predictive value $100 \%$, and the positive predictive value $31.8 \%$ (Table $4 \mathrm{~A}$ and $4 \mathrm{~B}$ )).

\begin{tabular}{|l|l|l|l|l|l|l|l|}
\hline \multicolumn{2}{|c|}{ Table (A) } & \multicolumn{3}{l|}{ Table (B) } \\
\hline & HPV+ & HPV- & Total & & HPV+ & HPV- & Total \\
\hline HSIL & 27 & 0 & 27 & SIL & 46 & 7 & 53 \\
\hline NO HSIL & 39 & 19 & 58 & NO SIL & 20 & 12 & 32 \\
\hline TOTAL & 66 & 19 & 85 & TOTAL & 66 & 19 & 85 \\
\hline
\end{tabular}


Page 3 of 5

\begin{tabular}{|c|c|}
\hline $\begin{array}{l}P=0.002 ; \quad \text { Sensitivity: } 100 \% \text {; } \\
\text { Specificity: } 32.8 \% \text {; PPV: } 39.4 \% \text {; NPV: } \\
100 \%\end{array}$ & $\begin{array}{l}\mathrm{P}=0.010 ; \quad \text { Sensitivity: } 86.8 \% \\
\text { Specificity: } 37.5 \% \text {; PPV: } 69.7 \% \text {; NPV: } \\
63.2 \%\end{array}$ \\
\hline
\end{tabular}

Table 4: Relationship between the HPV test and HSIL (a) or SIL (b) during the follow-up (A\&B).

Fifty three cases developed an intraepithelial lesion of some kind in the follow-up (SIL): 46 in the HPV+ group and 7 in the HPV-group, which resulted in a statistically significance difference $(\mathrm{p}=0.01)$. The sensitivity of the HPV test for a lesion of any grade was $86.8 \%$ the specificity $37.5 \%$, the negative predictive value $69.7 \%$ and the positive predictive value $63.2 \%$.

We studied the relationship between the morphological/cytological data and the HPV test (Table 5). Only coarse chromatin reached statistically significant association with the HPV test $(\mathrm{p}=0.007)$, with a sensitivity of $100 \%$, a specificity of $16.7 \%$, a negative predictive value of $78.3 \%$, and a positive predictive value of $100 \%$. Regarding the morphological data in cases for which follow-up data was available, coarse chromatin was related with the HPV positivity ( $p=0.007$;); Nuclear membrane irregularity showed a relationship with HSIL ( $\mathrm{p}=$ 0.015 with a sensitivity of $100 \%$, a specificity of $25 \%$, a negative predictive value of $100 \%$, and a positive predictive value of $30 \%$ ) in all cases and in HPV positive cases $(\mathrm{p}=0.003)$ (Table 5).

\begin{tabular}{|c|c|c|c|}
\hline & $\begin{array}{l}\mathrm{HPV}+/- \\
(\mathrm{n}=96)\end{array}$ & $\begin{array}{l}\text { FW } \\
(n=85)\end{array}$ & $\begin{array}{l}\text { FW HPV+ } \\
(n=66)\end{array}$ \\
\hline Isolated cells & $\begin{array}{l}\mathrm{P} \\
0.385\end{array}$ & $\begin{array}{l}\mathrm{P} \\
0.642\end{array}$ & $P=0.727$ \\
\hline Dyskeratosis & $\begin{array}{l}\mathrm{P} \\
0.507\end{array}$ & $\begin{array}{l}\mathrm{P} \\
0.880\end{array}$ & $P=0.705$ \\
\hline Hyperchromasia & $\begin{array}{l}\mathrm{P} \\
0.103\end{array}=$ & $\begin{array}{l}\mathrm{P} \\
0.221\end{array}=$ & $P=0.214$ \\
\hline Coarse chromatin & $\begin{array}{l}\mathrm{P} \\
0.007\end{array}$ & $\begin{array}{l}P \\
0.168\end{array}=$ & $P=0.273$ \\
\hline Nuclear membrane irregularity & $\begin{array}{l}\mathrm{P} \\
0.427\end{array}=$ & $\begin{array}{l}\mathrm{P} \\
0.015\end{array}=$ & $P=0.003$ \\
\hline 3D alteration & $\begin{array}{l}P \\
0.329\end{array}$ & $=P_{0.085}^{P}=$ & $P=0.071$ \\
\hline Molding & $\begin{array}{l}\mathrm{P} \\
0.293\end{array}$ & $\begin{array}{l}\mathrm{P} \\
0.235\end{array}$ & $P=0.046$ \\
\hline
\end{tabular}

HPV+/-. Result of HPV test $(n=96) ;$ FW: follow-up $(n=85) ;$ FW HPV+: Follow up only in cases HPV positive $(n=66)$

Table 5: Relationship between Morphological/Cytological Data, the HPV test, and the follow-up.

Molding was the morphological/cytological change related to HSIL in the follow-up ( $\mathrm{p}=0.046$,), only in HPV positive cases, but the sensitivity, specificity and predictive values were low (sensitivity: 47.6\%; specificity: $75.6 \%$; positive predictive value: $75.6 \%$; negative predictive value: $47.6 \%)$.

\section{Discussion}

ASCH is a cytological category recognized by Bethesda [1]. At least one third of these cases may correspond to HSIL lesions in the biopsy [13].

Some authors have emphasized the importance of ASCH diagnoses because they are closely related to HSIL lesions in the follow-up [2-12]. In addition, the relevance of HPV test has been reported for these cases as most of the HSIL that patients present during the clinical follow-up is strongly related to HPV positivity $[8,14-22]$. The present study highlights the importance of high negative predictive value of the HPV test in ASCH cases. Thus, we recommend that the HPV test be used for the management of patients with ASCH.

In our study, the incidence of HSIL during the follow-up was lower than that reported in previous studies $(24.7 \%$ vs. $28.3 \%$ to $65.5 \%$ reported) [2-4,6,8-10,23,24]. This finding could be attributed to underdiagnoses in our center. However, we also used a HPV test. In this regard, we believe that this test is of clinical use because all the HSIL cases were HPV+. Furthermore, the incidence of HSIL was not found to depend on the age of the patients-an observation that contrasts with other studies [9].

Regarding the age of the patients, the cases showed only a marginally significant difference with respect to the HPV test, but not related to high-grade lesions. Cervical lesions (of any grade) have been reported to be more frequent in women under 30 [2]. Moreover, those authors demonstrated that the incidence of HSIL is greater in younger women. However, our data are not consistent with those described in the literature either not related as the HPV-related cases (younger vs. older: SIL: 22 vs. 24 cases, SIL/HPV+: 24 vs. 29 cases, respectively). However, our results may be due to the low number of cases evaluated.

Among socio-demographical factors, we found no correlation with the development of HSIL during follow-up and smoking, nationality and contraception. The civil status (non-married vs. married) and the number of partners (more or less than 10) correlated in a statistically significant manner with the development of HSIL in the follow-up.

Finally, related to morphological/cytological data, our results show that some of the data are associated with the positivity of the HPV test (coarse chromatin) (Figure 1).

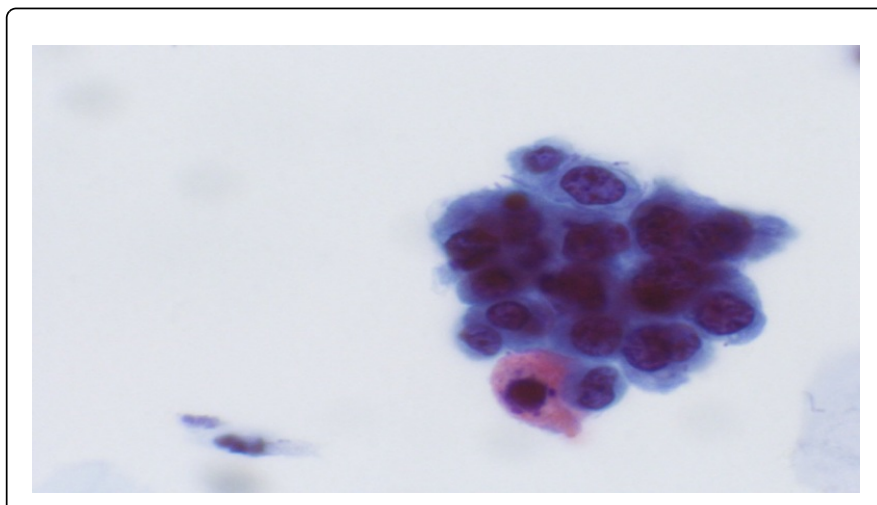

Figure 1: ASCH. Coarse chromatin Papanicolau X20.

And others with the development of HSIL in the follow-up (nuclear membrane irregularity and molding) (Figures 2 and 3). 
Citation: Hernández E, Del Amo E, Bellosillo B, Serrano L, Alameda F, et al. (2016) Squamous Cell Atypia Suggesting High-grade Lesions: Correlation of Morphological Data, HPV Test Results and Follow-up. J Cytol Histol 7: 396. doi:10.4172/2157-7099.1000396

Page 4 of 5

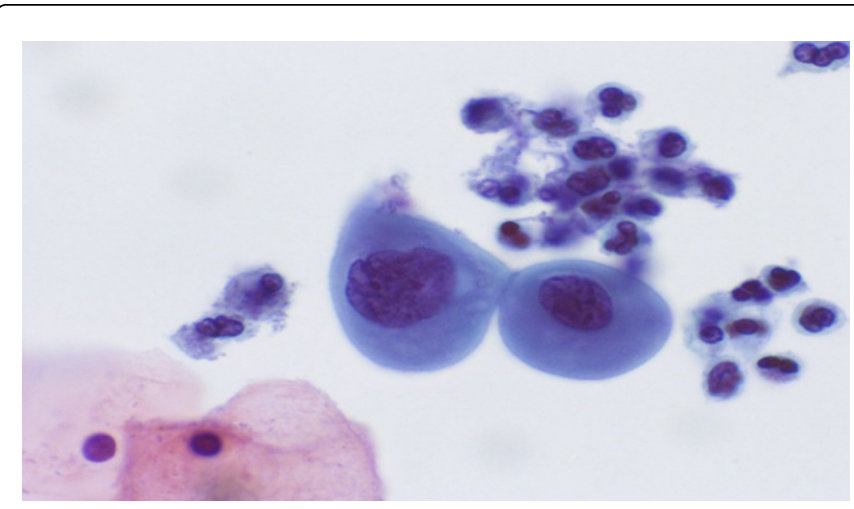

Figure 2: ASCH. Irregularities of nuclear membrane X20.

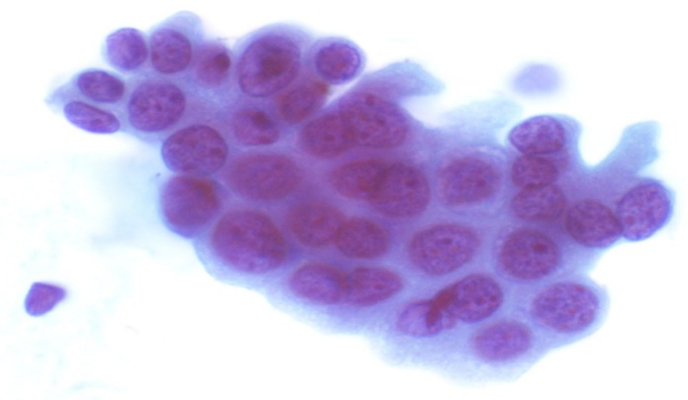

Figure 3: ASCH. Molding X 20.

The coarse chromatin in HPV+ cases can be associated with the higher frequency of aneuploidy observed in ASCH than in ASCUS [19] and in ASCH-HPV+ cases could indicate the presence of the virus into the nuclei. Some authors have shown that HPV positive cells incease the ploidy [26]. Thle inceasing of the ploidy is associated to CIN2+ in the follow-up

On the other hand, using SurePath', correlation between HSIL in the follow-up and altered nuclei/cytoplasm ratio, coarse chromatin, nuclear membrane irregularity, and hyperchromasia has been described as predictive in $\mathrm{ASCH}$, as has the number of atypical cells, molding, and nuclear alterations [23,24]. Other authors [27] have shown the association of cin2+ in the follow-up with high $\mathrm{N} / \mathrm{R}$ relationship, severe hypercromasia, nuclear membrane irregulariry and coarse chromatin. These authors do not include the possible relationship with HPV infection. In the present series, we demonstrated an association only between the irregularity of the nuclear membrane and HSIL in the follow-up. We did not evaluate the relationship with nuclear/cytoplasm alteration since such data are necessary for diagnosis of ASCH.

\section{Conclusions}

The HPV test has a predictive value for the follow-up of ASCH cases. There are the following associations between some morphological/cytological details in ASCH, the HPV test result, and the development of HSIL: coarse chromatin and HPV test result; nuclear membrane irregularity and HSIL in the follow-up, molding and HSIL in the follow-up in HPV+ cases.

\section{References}

1. Nayar R, Wilbur DC (2015) The Bethesda System for reporting cervical cytology (3rdedn) Springer New York.

2. Gilani SM, Tashjian R, Fathallah L (2014) Cervical cytology with a diagnosis of atypical squamous cells, cannot exclude high-grade squamous intraepithelial lesion (ASC-H): a follow-up study with corresponding histology and significance of predicting dysplasia by human papillomavirus (HPV) DNA testing. Arch Gynecol Obstet 289: 645-8.

3. Selvaggi SM (2013) Clinical significance of atypical squamous cells cannot exclude high grade squamous intraepithelial lesion with histologic correlation : a 9-year experience. Diagn Cytopathol 41: 943-946.

4. Bansal M, Li Z, Zhao C (2012) Correlation of histopathologic/cytologic follow-up findings with vaginal ASC-US and ASC-H Papanicolaou test and HPV test results. Am J Clin Pathol 137: 437- 443.

5. Cytryn A, Russomano FB, Camargo MJ, Zardo LM, Horta NM et al. (2009) Prevalence of cervical intraepithelial neoplasia grades II/III and cervical cancer in patients with cytological diagnosis of atypical squamous cells when high-grade intraepithelial lesions (ASC-H) cannot be ruled out. Sao Paulo Med J 127: 283-287.

6. Song JS, Hwang I, Gong G (2012) Outcome of "atypical squamous sells" in cervical cytology: follow-up assessment by Loop Electrical Excision Procedure. Korean J Pathol 46: 359-64.

7. Barcelos AC, Michelin MA, Adad SJ, Murta EF (2011) Atypical squamous cells of undetermined significance: Bethesda classification and association with Human Papillomavirus. Infect Dis Obstet Gynecol, Epub.

8. Barreth D, Schepansky A, Capstick V, Jonson G, Steed H, et al. (2006) Atypical squamous cells cannot exclude high-grade squamous intraepithelial lesion (ASC-H): a result not to be ignored. J Obstet Gynaecol Can 28: 1095-1098.

9. López-Alegría F, De Lorenzi DS, Quezada OP (2014) Follow-up of women with atypical squamous cells cannot exclude high-grade squamous intraepithelial lesions (ASC-H). Sao Paulo Med J 132:15-22.

10. Sung CO, Oh YL, Song SY (2011) Cervical cytology of atypical squamous cells, cannot exclude high-grade squamous intra-epithelial lesion: significance of age, human papillomavirus DNA detection and previous abnormal cytology on follow-up outcomes. Eur J Obstet Gynecol Reprod Biol 159: 155-9.

11. Davey DD, Greenspan DL, Kurtycz DF, Husain M, Austin RM (2010) Atypical squamous cells, cannot exclude high-grade squamous intraepithelial lesion: review of ancillary testing modalities and implications for follow-up. J Low Genital Tract Dis 14: 206-214.

12. You K, Guo Y, Gen L, Qiao J (2010) The risk of CIN II or greater in a oneyear follow-up period in patients with ASC-H interpreted with cytology. Eur J Obstet Gynecol Reprod Biol 149: 215-217.

13. Torne A, Del Pino M, Cusido M, Alameda F, Andia D et al. (2014) Guidelines for the screening of cervical cancer in Spain. Rev Esp Patol 47: 1- 43.

14. Lee S, Kim JW, Hong JH, Song JY, Lee JK, et al. (2014) Clinical significance of HPV DNA cotesting in Korean women with ASCUS or ASC-H. Diagn Cytopathol 42: 1058-1062.

15. Biu H, Zhao J, Li KM, Liao QP (2009) The significance of HPV-DNA genotyping assays in the ASC. Zhonghua Shi Yan He Lin Chuang Bing Du Xue Za Zhi 23: 296-298.

16. Zivadinovic R, Lilic V, Dordevic B, Stanojevic Z, Petric A et al. (2009) The role of colposcopy and typization of human papillomavirus in further diagnostic proceedings in patients with ASC-US cytological finding of the uterine cervix. Vojnosanit Pregl 66: 651-655. 
Citation: Hernández E, Del Amo E, Bellosillo B, Serrano L, Alameda F, et al. (2016) Squamous Cell Atypia Suggesting High-grade Lesions: Correlation of Morphological Data, HPV Test Results and Follow-up. J Cytol Histol 7: 396. doi:10.4172/2157-7099.1000396

Page 5 of 5

17. Reid-Nicholson M, Gatscha RM, Riedel ER, Lin O (2007) Atypical squamous cells, cannot exclude high grade intraepithelial lesion (ASC-H). Does HPV matter? Diagn Cytopathol 35: 1-5.

18. Bandyopadhyay S, Austin RM, Dabbs D, Zhao C (2008) Adjunctive human papillomavirus DNA testing is a useful option in some clinical settings for disease risk assessment and triage of females with ASC-H Papanicolaou test results. Arch Path Lab Med 132: 1874-81.

19. Mei P, Liu YH, Li M, Lou XL, Zhuang HG, et al. (2009) Significance of high-risk HPV DNA in ASC-H. Significance of high-risk human papillomavirus DNA in atypical squamous cells, cannot exclude highgrade squamous intraepithelial lesion. Zhonghua Bing Li Xue Za Zhi 38: 337-9.

20. Rao A, Pather S, Dalrymple C, Mackie A, Deans R, et al. (2009) The role of HPV testing in patients with possible high-grade cervical cytology. J Obstet Gynaecol Res 35: 503-506.

21. Zhao C, Zhao S, Heider A, Austin RM (2010) Significance of high-risk human papillomavirus DNA detection in women 50 years and older with squamous cell papanicolaou test abnormalities. Arch Pathol Lab Med 134: 1130-1135.

22. Cohen D, Austin RM, Gilbert C, Freij R, Zhao C (2012) Follow-up outcomes in a large cohort of patients with human papillomavirusnegative ASC-H cervical screening test results. Am J Clin Pathol 138: 517-23.
23. Atjimakul T, Boonyapipat S, Chichareon S, Phukaoloun M (2013) Cytomorphologic and clinical factors of having high-grade cervical intraepithelial neoplasia/invasive carcinoma in women with atypical squamous cells, cannot exclude high-grade squamous intraepithelial lesion (ASC-H) smears. J Med Assoc Thai 96: 1389-94.

24. Gupta N, Crossely J, Dudding N, Ellis K, Smith JH (2013) Atypical squamous cells, cannot exclude high-grade squamous intraepithelial lesion: diagnostic features in surepath $^{\text {TM }}$ cervical samples. Diagn Cytopathol 41: 520-6.

25. Schiffman M, Herrero R, Hildesheim A, Sherman ME, Bratti M, et al. (2000) HPV DNA testing in cervical cancer screening: results from women in a high-risk province of Costa Rica. JAMA 283: 87-93.

26. Lorenzato M1, Caudroy S, Nou JM, Dalstein V, Joseph K, et al. (2008) Contribution of DNA ploidy image cytometry to the management of ASC cervical lesions. Cancer 114: 263-269.

27. Atijmakul T, Boonyapipat S, Chichareon S, Phukaoloun M (2013) Cytomorphologic and clinical facturs of having high-grade cervical intraepithelial neoplasia/invasive carcinoma in women with atypical squamous cells, cannot exclude high-grade squamous intraepithmelial lesion (ASC-H) smears. J Med Assoc Thai 96: 1389-94 